\title{
Lobe of the Right Lung
}

National Cancer Institute

\section{Source}

National Cancer Institute. Lobe of the Right Lung. NCI Thesaurus. Code C48944.

One of the three lobes that comprise the right lung. 